\title{
Prevalence of Traumatic Dental Injuries to the Permanent Anterior Teeth among 9- to 14-year-old Schoolchildren of Navi Mumbai (Kharghar-Belapur Region), India
}

\author{
${ }^{1}$ Rahul Hegde, ${ }^{2}$ Geet Agrawal
}

\begin{abstract}
Aims and objectives: To measure the prevalence of anterior teeth trauma in 9- to 14-year-old schoolchildren and their association with predisposing factors, such as lip competence, molar relationship, overjet, and variables, such as age, gender, and cause of trauma.
\end{abstract}

Materials and methods: Epidemiological cross-sectional study was carried out among 3,012 schoolchildren aged 9 to 14 years in Navi Mumbai (Kharghar-Belapur region). The sample size was derived using the stratified random sampling method; we picked six schools from the region. These schools had 3,000 students in the acceptable age group of the study which constituted our final sample size. All children were examined for traumatic dental injuries, and the children with positive findings were further examined for lip competence, Angle's molar relationship, and overjet. The results were statistically analyzed using cross-tabulation and Chi-square test.

Results: The prevalence of dental injuries was $7.3 \%$, and the ratio of male to female children was found to be 1.6:1. The maximum number of traumatic dental injuries was found with class I molar relationship and overjet less than $3.5 \mathrm{~mm}$ in children with competent lips. Maximum number of injuries occurred in the age group of 13-14 years. The most predominant type of injury was the enamel fracture and the most common cause determined was due to fall.

Conclusion: The present study is a collection of data on traumatic injuries to anterior teeth, which is seen very commonly in day-to-day practice. The frequency and cause of traumatic injuries to anterior teeth is important for identification of risk groups, treatment needs, and cost involved in order for establishing effective preventive measures.

Keywords: Anterior teeth trauma, Dental trauma, Permanent anterior teeth, Risk factors, Traumatic dental injury.

How to cite this article: Hegde R, Agrawal G. Prevalence of Traumatic Dental Injuries to the Permanent Anterior Teeth among 9- to 14-year-old Schoolchildren of Navi Mumbai (Kharghar-Belapur Region), India. Int J Clin Pediatr Dent 2017;10(2):177-182.

\footnotetext{
${ }^{1}$ Professor and Head, ${ }^{2}$ Assistant Professor

1,2Department of Pedodontics and Preventive Dentistry, Bharati Vidyapeeth Deemed University Dental College \& Hospital, Navi Mumbai, Maharashtra, India

Corresponding Author: Geet Agrawal, Assistant Professor Department of Pedodontics and Preventive Dentistry, Bharati Vidyapeeth Deemed University Dental College \& Hospital, Navi Mumbai, Maharashtra, India, Phone: +912227564654, e-mail: geet.pedo@gmail.com
}

\section{Source of support: Nil}

Conflict of interest: None

\section{INTRODUCTION}

An individual's quality of life is strongly influenced by their health condition. In the field of dental health, physical constraints may directly influence aspects of feeding, speech, social interaction and self-esteem, and psychology. ${ }^{1}$ It is accepted that the position and appearance of the anterior teeth have psychological and social impact on children. ${ }^{2}$ Therefore, it is not surprising that dental problems are linked to social and psychological and emotional well-being. The contribution of dentofacial characteristics to dimensions of personality, self-esteem, and body image is well documented. ${ }^{3}$ Most of the literature found on dental injury pertains to the classification, incidence, prevalence, and treatment of fractured teeth. A major finding here is that the five leading causes of dentofacial injuries, regardless of severity, were falls, being struck by an object, bicycle accidents, assaults, and motor vehicle accidents. ${ }^{4}$ Trauma along with fracture of a permanent front tooth is a disturbing experience for the young patient and is a problem whose management requires experience, judgment, and skill perhaps incomparable to any other segment of the dental practice. The dentist whose counsel is sought after a trauma should treat the patient with all possible means or immediately refer the patient to a specialist. The oral and emotional health of the young patient is involved and the child's appearance, marred by an unsightly oral injury, must be restored to normal as soon as possible to relieve the consciousness of being different from other children. ${ }^{5}$ Providing education to individuals who supervise and look after the children and would be in close proximity to the accident site of traumatic dental injury (TDI) has been widely advocated. ${ }^{6}$ These educational programs should explain the importance of prompt treatment for dental trauma, including ways of preventing these traumas and procedures for apt emergency management to be instituted. Such educational programs for the general public in a region should be preceded by an analysis of background information on the incidence of orodental injuries in that community.

This served as the motivation for our present study to evaluate the prevalence of the traumatic injuries to the 
anterior teeth in schoolgoing children of Kharghar and Belapur region, Navi Mumbai, India, and to correlate the prevalence of injury to the cause of trauma with the age of the child, the incisal overjet, molar relation, and lip competence of the child.

\section{MATERIALS AND METHODS}

The study consists of 3,012 primary and high schoolgoing children of both genders aged between 9 and 14 years selected by using stratified random sampling method. The sample size was derived from the population of 9- to 14-year-old schoolgoing children in the given area. There are currently 40,000 children studying in 22 schools in the Kharghar-Belapur region. Using the stratified random sampling method, we picked six schools from the region. These schools had 3,000 students in the acceptable age group of the study, which constituted our final sample size. Children with permanent anterior teeth lost due to caries or causes other than trauma or with partial or complete anodontia involving permanent anterior teeth were excluded. Informed consent was taken from the concerned school authorities and from all individual participants included in the study before the commencement of the survey. All the information regarding gender, age, number of injured teeth, type of the teeth, type of injury (treated and untreated), cause of injury, lip competence, the molar relationship, and overjet was carefully recorded. Children were divided in three age groups of 9 to 10,11 to 12 , and 13 to 14 years to find the age-wise prevalence of trauma. The examination was done using Andreasen's epidemiological classification of TDIs including codes of the World Health Organization international classification of diseases to dentistry and stomatology (1997) by only one examiner. For the measurement of overjet, calibrations on the
Community Periodontal Index of Treatment Needs probe were used, i.e., 3.5, 5.5, 8.5, and $11.5 \mathrm{~mm}$. The children with TDIs were also observed for lip competence, and the molar relationships were recorded following Angle's classification. The Federation Dentaire Internationale system of tooth numbering is followed in the study. The children were verbally asked to state the cause of the injury, which was documented under the categories of fall, collision, road accident, violence, cannot recollect, and miscellaneous. Miscellaneous category included biting on hard objects, such as pencil, pen, etc., and improper use of teeth, such as opening of bobby pins and soda pop bottles. The analysis of the data was done by using descriptive statistics (frequency distribution and cross-tabulation). Statistical significance of the association between the occurrence of the dental injuries and gender, age, cause, and overjet was tested using the chi-square test.

\section{OBSERVATION AND RESULTS}

From the overall 220 cases of traumatic injuries, in 136 cases $(61.8 \%)$, the cause of trauma was found to be falls; 45 cases $(20.5 \%)$ were caused due to collision; 11 cases $(5 \%)$ were caused due to accident; 7 cases (3.2\%) were caused due to violence; 9 cases $(4.1 \%)$ could not recollect; 12 cases $(5.4 \%)$ fell under the miscellaneous (Table 1 ) category. In the age-wise comparison of prevalence of TDIs, the prevalence was more in 13- to 14-year-old males (55 cases; $25 \%$ ) than females (38 cases; $17.2 \%$ ) when compared with age groups of 9 to 10 and 11 to 12 years (Table 2). It was observed that the maximum number of TDIs was found with tooth type XI (135 cases; 50\%) followed by 21 (71 cases; $25.9 \%$ ). The most common type of TDI seen was code 2 (152 cases; $55.5 \%$ ) in both males and females (Table 3); 89.1\% TDIs were observed with

Table 1: Descriptive statistics showing the cause of TDIs in males and females

\begin{tabular}{|c|c|c|c|c|c|c|c|c|}
\hline \multirow[b]{2}{*}{ Cause of injury } & \multicolumn{2}{|c|}{ Male } & \multicolumn{2}{|c|}{ Female } & \multicolumn{2}{|c|}{ Total } & \multicolumn{2}{|c|}{ Chi-square test* } \\
\hline & No. & $\%$ & No. & $\%$ & No. & $\%$ & $\chi^{2}$ & $p$-value \\
\hline Fall & 83 & 61.10 & 53 & 63.20 & 136 & 61.8 & 4.197 & 0.040 \\
\hline Collision & 34 & 25 & 11 & 13 & 45 & 20.5 & 7.053 & 0.008 \\
\hline Accident & 6 & 4.40 & 5 & 6 & 11 & 5 & 0.015 & 0.902 (NS) \\
\hline Violence & 6 & 4.40 & 1 & 1.10 & 7 & 3.2 & 1.237 & 0.266 \\
\hline Cannot recollect & 4 & 2.90 & 5 & 6 & 9 & 4.1 & 0.018 & 0.891 \\
\hline Miscellaneous & 3 & 2.30 & 9 & 10.70 & 12 & 5.4 & 1.157 & 0.282 \\
\hline Total & 136 & 100 & 84 & 100 & 220 & 100 & 7.776 & 0.005 \\
\hline
\end{tabular}

NS: Not significant; *Within gender comparison

Table 2: Descriptive statistics showing the prevalence of TDIs in both males and females in different age groups

\begin{tabular}{|c|c|c|c|c|c|c|c|c|}
\hline \multirow{2}{*}{$\begin{array}{l}\text { Age group } \\
\text { (years) }\end{array}$} & \multicolumn{2}{|c|}{ Male } & \multicolumn{2}{|c|}{ Female } & \multicolumn{2}{|c|}{ Total } & \multicolumn{2}{|c|}{ Chi-square test* } \\
\hline & No. & $\%$ & No. & $\%$ & No. & $\%$ & $\chi^{2}$ & $p$-value \\
\hline $9-10$ & 45 & 20.4 & 23 & 10.4 & 68 & 30.8 & 4.169 & 0.142 \\
\hline $11-12$ & 36 & 16.3 & 23 & 10.4 & 59 & 26.7 & 1.502 & 0.220 \\
\hline $13-14$ & 55 & 25.0 & 38 & 17.2 & 93 & 42.2 & 1.729 & 0.078 \\
\hline Total & 136 & 61.7 & 84 & 38.0 & 220 & 99.7 & 44.188 & $<0.0001$ \\
\hline
\end{tabular}

*Within age group comparison (male $v s$ female) 


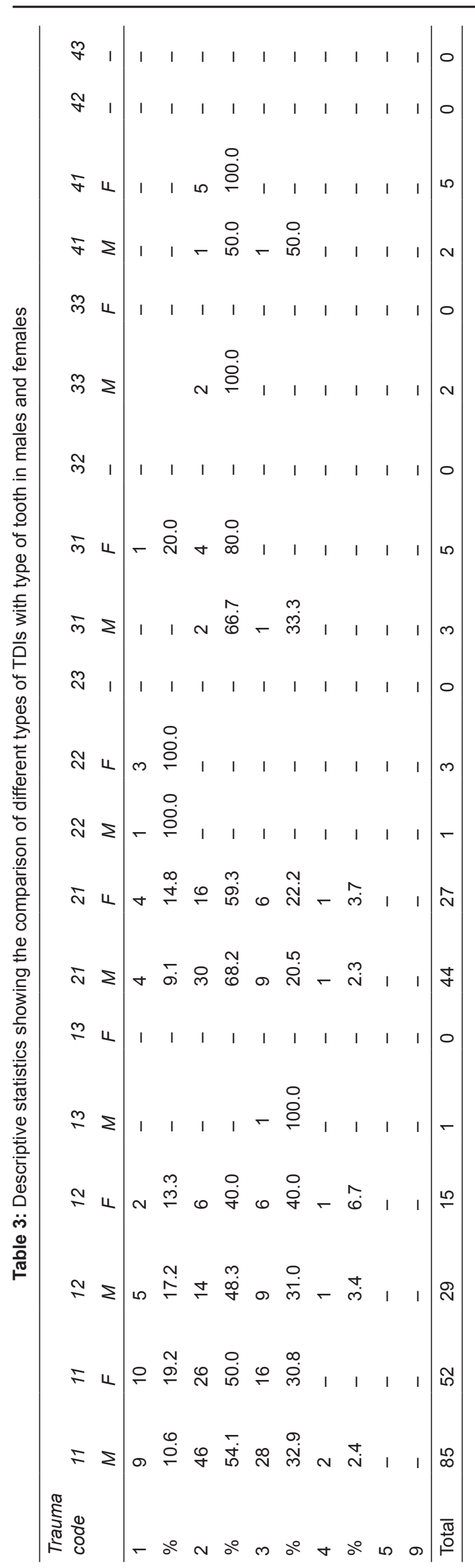

an overjet of $<3.5 \mathrm{~mm}, 7.7 \%$ TDI was observed with an overjet of 3.6-5.5 mm, 2.9\% TDI was observed with an overjet of $5.6-8.5 \mathrm{~mm}$, and $0.4 \%$ TDI was observed with an overjet of $8.6-11.5 \mathrm{~mm}$ in anterior teeth in both males and females. The maximum number of TDIs was found with an overjet of $<3.5 \mathrm{~mm}$ in both males and females (Table 4). More number of TDIs was found in children with competent lips (206 cases; 93.6\%) (Table 5). Prevalence of trauma was found to be more in maxillary arch as compared with mandibular arch in both males and females (Table 6). High prevalence of TDI was seen in children with class I molar relationship as compared with class II and III molar relationship (Table 7).

\section{DISCUSSION}

This cross-sectional survey has identified a prevalence of $7.3 \%$ of TDIs to the permanent anterior teeth among schoolgoing children aged 9 to 14 years in Navi Mumbai (Kharghar-Belapur region). The prevalence noted in the present study was lower as compared with the earlier studies done by Soriano et $\mathrm{al}^{8}$ in which the prevalence of TDIs was $23.3 \%$. In a study conducted by Dua and Sharma, ${ }^{9}$ the prevalence of TDIs of $14.5 \%$ was found. The prevalence was higher than the study conducted by NikHussein ${ }^{10}$ where a prevalence of $4.1 \%$ was found. There may be several reasons for this variation of prevalence between different studies. This could be due to the age of the study subjects, gender, sample size, and criteria used. The male/female ratio was found to be 1.6:1. The male/female ratio was in accordance with the results of a study conducted by Hamdan and Rock ${ }^{11}$ where the male to female ratio was 1.7:1. A possible reason for boys being more prone to TDIs could be their participation and involvement in more aggressive sports and outdoor activities than girls. Violence has also been suggested as a reason of more TDIs in boys. The relatively low prevalence of trauma among girls can also be explained by the fact that girls are in general more mature in their behavior when compared with boys, who tend to be more energetic and inclined toward exuberant outdoor activities. In this study, the peak age to sustain injury was found to be in the age group of 13 to 14 years in both boys and girls, which is similar to the study conducted by Govindarajan et $\mathrm{al}^{12}$ in which more number of injuries was found in 10- to 13-year-old children. The cause of injury can differ according to age, gender, level of activity of the child. In our study, the most common cause of traumatic injuries was "fall" followed by collision. The results are in accordance with a study conducted in southern India by Rai and Munshi ${ }^{13}$ and also with the study conducted by Dua and Sharma ${ }^{9}$ where they found "fall" as the most common cause of TDI. 


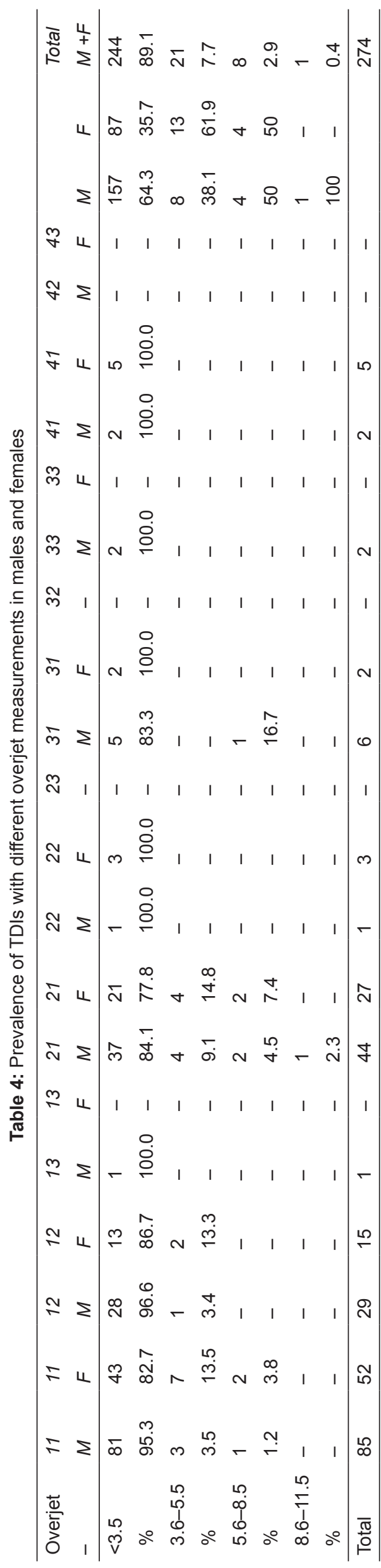

Table 5: Descriptive statistics showing the comparison of lip competence in the affected children and its association with TDIs

\begin{tabular}{|c|c|c|c|c|c|c|}
\hline \multirow{2}{*}{$\begin{array}{l}\text { Lip } \\
\text { competence }\end{array}$} & \multicolumn{2}{|c|}{ Male $(n=136)$} & \multicolumn{2}{|c|}{ Female $(n=84)$} & \multicolumn{2}{|c|}{ Chi-square test } \\
\hline & No. & $\%$ & No. & $\%$ & $\overline{\chi^{2}}$ & $p$-value \\
\hline Compete & 128 & 94.10 & 78 & 92.8 & 0.007 & 0.930 \\
\hline Incompetent & 8 & 5.90 & 6 & 7.2 & & \\
\hline
\end{tabular}

In the present study the most common type of TDI was found to be enamel fracture. Garcia-Godoy et $\mathrm{al}^{14}$ in their study reported enamel fracture as the most common type of dental injuries, accounting for about $50 \%$ of dental injuries. The result derived in our study was unlike the result of the study conducted by Rajab et al ${ }^{15}$ where the most common type of crown injury found to be was enamel and dentin fracture. The relationship between overjet with TDI has been investigated extensively by different authors and has yielded conflicting results. In the present study, no statistically significant relationship has been observed between the overjet and TDI. This result is in accordance with the study by Stokes et $\mathrm{al}^{16}$ where no significant difference in the means of overjet sizes between the injury group and the control group was found. Petti et $\mathrm{al}^{17}$ reported that individuals with overjet greater than $3 \mathrm{~mm}$ were two and half times more at risk when compared with individuals who had a normal overjet. Nevertheless, the present study did not find a positive association, as also asserted in a study by Kumar et al, ${ }^{18}$ who showed an insignificant relation between overjet and TDIs in their study. The reason for such variation in our study can be due to the large population of children with overjet more than $3.5 \mathrm{~mm}$. It is an attention-grabbing question as to why the results of these studies differ so much. It may be because of the investigated populations, the sample sizes, the ways and means of measurement, intraexaminer consistency, reliability, and so on that differ from study to study.

The association between dental trauma and lip coverage is not well defined in the literature. In the present study, no statistically significant relationship has been observed between the lip coverage and TDIs. Some studies have shown this association. In studies conducted by Cortes et al, ${ }^{19}$ more number of injuries was observed with inadequate lip coverage. Traebert et $\mathrm{al}^{20} \mathrm{did}$ not find any association between inadequate lip coverage and TDI in their study. Glendor reported that these differing results may be due to the interaction between oral predisposing factors and environmental and behavioral factors. ${ }^{21}$ Cases with class I molar relation were found to exhibit large number of TDIs followed by class II div 1 malocclusion. This result is in accordance with the result of the study conducted by Govindarajan et $\mathrm{al}^{12}$ in schoolchildren of Tamil Nadu, India. In the study done by 
Prevalence of TDIs to the Permanent Anterior Teeth among 9- to 14-year-old Schoolchildren of Navi Mumbai

Table 6: Frequency distribution of trauma between the maxillary and mandibular arches

\begin{tabular}{|c|c|c|c|c|c|c|c|c|}
\hline \multirow[b]{2}{*}{ Arch } & \multicolumn{2}{|c|}{ Males $(n=167)$} & \multicolumn{2}{|c|}{ Females $(n=107)$} & \multicolumn{2}{|c|}{ Total teeth $(n=274)$} & \multicolumn{2}{|c|}{ Chi-square test* } \\
\hline & No. & $\%$ & No. & $\%$ & No. & $\%$ & $\chi^{2}$ & $p$-value \\
\hline Maxillary arch & 160 & 95.90 & 97 & 90.60 & 257 & 93.8 & 9.877 & 0.002 \\
\hline Mandibular arch & 7 & 4.10 & 10 & 9.40 & 17 & 6.2 & 0.088 & 0.041 \\
\hline Chi-square test ${ }^{\star *}$ & $\begin{array}{l}\chi^{2} \\
101.05\end{array}$ & $\begin{array}{c}\mathrm{p} \\
<0.0001\end{array}$ & $\begin{array}{l}\chi^{2} \\
49.158\end{array}$ & $\begin{array}{l}\mathrm{p} \\
<0.0001\end{array}$ & $\begin{array}{l}\chi^{2} \\
151.297\end{array}$ & $\begin{array}{c}\mathrm{p} \\
<0.0001\end{array}$ & & \\
\hline
\end{tabular}

*Within age group comparison; ** within-gender comparison

Table 7: Descriptive statistics showing the comparison of molar relationship in the prevalence of TDIs in males and females

\begin{tabular}{lllllllll}
\hline Molar relationship & Males & $\%$ & Females & $\%$ & Total (Male + female) & $\%$ & Chi-square & $p$-value \\
\hline Class I & 119 & 87.6 & 75 & 89.2 & 194 & 88.2 & 6.243 & 0.012 \\
Class II & 6 & 4.4 & 1 & 1.1 & 7 & 3.1 & 1.237 & 0.266 \\
Class II div 1 & 10 & 7.3 & 8 & 9.7 & 18 & 8.2 & 0.009 & 0.923 \\
Class II div 2 & - & - & - & - & - & - & - & - \\
Class III & 1 & 0.7 & 0 & - & 1 & 0.5 & - & - \\
Total & 136 & 100 & 84 & $100 \%$ & 220 & 100 & 7.776 & 0.005 \\
Chi-square & & & & & 216.76 & & \\
p-value & & & & & $<0.0001$ & & \\
\hline
\end{tabular}

Rai and Munshi ${ }^{13}$ in Southern India, the highest number of TDIs was associated with class II div 1. Advanced studies are needed to know the factors that increase the risk of damage to the permanent anterior dentition. Such piece of data is essential to develop and execute effectual preventive approaches for reducing the prevalence of this condition. To understand the complexities of dental trauma epidemiology, additional prospective studies are required on representative populations that will help in implementation of preventive strategies to reduce the frequency of dental trauma.

\section{CONCLUSION}

Prevalence of TDIs to anterior teeth in schoolchildren of Navi Mumbai (Kharghar-Belapur region) is 7.3\%. Males are found to have experienced greater TDIs as compared with females. The most common cause of trauma was found to be fall. The teeth most commonly involved with trauma were maxillary central incisors. The most common type of TDI was enamel fracture. Children (both male and female) in the age group of 13-14 years have experienced highest trauma, when compared with children in the age group of 9-10 and 11-12 years. There was no statistically significant correlation found between overjet, lip competence, and molar relationship with the prevalence of trauma to anterior teeth in the selected population.

This article is significant for pediatric dentists as there are limited studies concerning TDI in young permanent dentition. It offers information about behavioral and anthropometric risk factors for the incidence of TDIs in schoolgoing children. These findings can help pediatric dentists in clinical practice and elaboration of prevention strategies of TDI at the population level.

\section{REFERENCES}

1. Traebert J, Lacerda JT, Foster Page LA, Thomson WM, Bortoluzzi MC. Impact of traumatic dental injuries on the quality of life of schoolchildren. Dent Traumatol 2012 Dec;28(6): 423-428.

2. Cortes MI, Marcenes W, Sheiham A. Impact of traumatic injuries to the permanent teeth on the oral health-related quality of life in 12-14-year-old children. Community Dent Oral Epidemiol 2002 Jun;30(3):193-198.

3. Andreasen, JO.; Andreasen, FM.; Andersson, L. Textbook and color atlas of traumatic injuries to the teeth. 4 th ed. Oxford: Blackwell Munksgaard; 2007.p. 217-254.

4. Harrington MS, Eberhart AB, Knapp JF. Dentofacial trauma in children. ASDC J Dent Child 1988 Sep-Oct;55(5): 334-338.

5. McDonald, RE.; Avery, DR.; Dean, JA. Management of trauma to the teeth and supporting tissues. In: Dentistry for the child and adolescent. St. Louis (MO): Mosby; 2004.p. 454-503.

6. McIntyre JD, Lee JY, Trope M, Vann WF Jr. Effectiveness of dental trauma education for elementary school staff. Dent Traumatol 2008 Apr;24(2):146-150.

7. Kahabuka FK, Plasschert A, van't Hof M. Prevalence of teeth with untreated dental trauma among nursery and primary school pupils in Dares Salaam, Tanzania. Dent Traumatol 2001 Jun;17(3):109-113.

8. Soriano EP, Caldas AF Jr, Góes PS. Risk factors related to traumatic dental injuries in Brazilian schoolchildren. Dent Traumatol 2004 Oct;20(5):246-250.

9. Dua R, Sharma S. Prevalence, causes, and correlates of traumatic dental injuries among seven-to-twelve-year-old school children in Dera Bassi. Contemp Clin Dent 2012 Jan;3(1): 38-41.

10. Nik-Hussein NN. Traumatic injuries to anterior teeth among schoolchildren in Malaysia. Dent Traumatol 2001 Aug;17(4):149-152.

11. Hamdan MA, Rock WP. A study comparing the prevalence and distribution of traumatic dental injuries among 10-12-year-old children in an Urban and in a rural area of Jordan. Int J Paediatr Dent 1995 Dec;5(4):237-241. 
12. Govindarajan M, Reddy VN, Ramalingam K, Durai KS, Rao PA, Prabhu A. Prevalence of traumatic dental injuries to the anterior teeth among three to thirteen-year-old school children of Tamilnadu. Contemp Clin Dent 2012 Apr;3(2): 164-167.

13. Rai SB, Munshi AK. Traumatic injuries to the anterior teeth among South Kanara school children- a prevalence study. J Indian Soc Pedod Prev Dent 1998 Jun;16(2):44-51.

14. Garcia-Godoy F, Sánchez R, Sánchez JR. Traumatic dental injuries in a sample of Dominican schoolchildren. Community Dent Oral Epidemiol 1981 Aug;9(4):193-197.

15. Rajab LD, Baqain ZH, Ghazaleh SB, Sonbol HN, Hamdan MA. Traumatic dental injuries among 12-year-old schoolchildren in Jordan: prevalence, risk factors and treatment need. Oral Health Prev Dent 2013;11(2):105-112.

16. Stokes AN, Loh T, Teo CS, Baqramian RA. Relation between incisal overjet and traumatic injury: a case control study. Endod Dent Traumatol 1995 Feb;11(1):2-5.
17. Petti S, Cairella G, Tarsitani G. Childhood obesity: a risk factor for traumatic injuries to anterior teeth. Endod Dent Traumatol 1997 Dec;13(6):285-288.

18. Kumar A, Bansal V, Veeresha KL, Soqi GM. Prevalence of traumatic dental injuries among 12- to 15-year-old schoolchildren in Ambala district, Haryana, India. Oral Health Prev Dent 2011;9(3):301-305

19. Cortes MI, Marcenes W, Sheiham A. Prevalence and correlates of traumatic injuries to the permanent teeth of schoolchildren aged 9-14 years in Belo Horizonte, Brazil. Dent Traumatol 2001 Feb;17(1):22-26.

20. Traebert J, Peres MA, Blank V, Böell Rda S, Pietruza JA. Prevalence of traumatic dental injury and associated factors among 12-year-old school children in Florianopolis, Brazil. Dent Traumatol 2003 Feb;19(1):15-18.

21. Glendor U. Aetiology and risk factors related to traumatic dental injuries - a review of the literature. Dent Traumatol 2009 Feb;25(1):19-31. 